Louisiana State University

LSU Digital Commons

12-1-1995

\title{
Crystal structure of a remarkably ruffled nonplanar porphyrin (pyridine)[5,10,15,20-tetra(tert-butyl)porphyrinato]zinc(II)
}

\author{
Mathias O. Senge \\ University of California, Davis \\ Tadashi Ema \\ University of California, Davis \\ Kevin M. Smith \\ University of California, Davis
}

Follow this and additional works at: https://digitalcommons.Isu.edu/chemistry_pubs

\section{Recommended Citation}

Senge, M., Ema, T., \& Smith, K. (1995). Crystal structure of a remarkably ruffled nonplanar porphyrin (pyridine)[5,10,15,20-tetra(tert-butyl)porphyrinato]zinc(II). Journal of the Chemical Society, Chemical Communications (7), 733-734. https://doi.org/10.1039/C39950000733

This Article is brought to you for free and open access by the Department of Chemistry at LSU Digital Commons. It has been accepted for inclusion in Faculty Publications by an authorized administrator of LSU Digital Commons.

For more information, please contact ir@lsu.edu. 


\title{
Crystal Structure of a Remarkably Ruffled Nonplanar Porphyrin (Pyridine) [5, 10,15,20-Tetra(tert-butyl)porphyrinato]zinc(II)
}

\author{
Mathias O. Senge, ${ }^{*}+$ Tadashi Ema and Kevin M. Smith* \\ Department of Chemistry, University of California, Davis, CA 95616, USA
}

The title compound presents the first example of a sterically ruffled porphyrin bearing only meso substituents; the degree of ruffling is severe, with $C_{m}$-displacements of up to $1 \AA$.

Recent synthetic and structural studies on porphyrins have concentrated on investigations of porphyrin nonplanarity induced by peripheral steric strain. ${ }^{1}$ Examples of conformationally designed porphyrins, specifically synthesized to yield porphyrins with nonplanar macrocyclic conformations and whose structures have been determined by $\mathrm{X}$-ray crystallography are octaethyltetraphenylporphyrin $\left(\mathrm{H}_{2} \mathrm{OETPP}\right){ }^{2}$ dodecaphenylporphyrin, ${ }^{3}$ octahalogenotetrarylporphyrins, ${ }^{4}$ octaethyltetranitroporphyrin $^{5}$ and tetracycloalkenyltetraphenylporphyrins. ${ }^{2 b, 6}$ All these compounds exhibit striking nonplanar macrocyclic conformations and they share the common feature of substitution with alkyl and/or aryl substituents at all meso- and $\beta$-pyrrole positions of the macrocycle. While significant differences in physicochemical properties in comparison to planar porphyrins such as tetraphenyl- or octaethyl-porphyrin were observed for these dodecasubstituted porphyrins, their general chemical behaviour nonetheless was similar to that of 'normal' planar porphyrins. We have recently established that introduction of extremely bulky groups at the meso positions alone leads to porphyrins with considerably altered chemistry, and on the basis of their spectroscopic characteristics inferred a distorted macrocyclic conformation for compounds like 5,10,15,20-tetra(tertbutyl)porphyrin $\left(\mathrm{H}_{2} \mathrm{TtBuP}\right){ }^{7}$

While nonplanar porphyrins such as $\mathrm{H}_{2} \mathrm{OETPP}$ undergo metallation and protonation reactions in a manner similar to that of their planar counterparts, $\mathrm{H}_{2} \mathrm{TtBuP}$ yielded ${ }^{7}$ porphodimethene products [related to 5-hydro-15-methoxy5,10,15,20-tetra(tert-butyl)porphyrin] when treated under standard conditions with zinc(II) acetate in methanol-chloroform or with methanolic $\mathrm{HClO}_{4}$. 'Normal' metal complexes or dications could be prepared only through careful and very brief treatment of the porphyrin $\left(\mathrm{H}_{2} \mathrm{TtBuP}\right)$ with appropriate reagents. We attribute the unexpected reactivity in $\mathrm{H}_{2} \mathrm{TtBuP}$ (compared with planar porphyrins or even nonplanar porphyrins such as $\mathrm{H}_{2} \mathrm{OETPP}$ ) to the severe steric congestion resulting from the presence of the tert-butyl groups, which is presumably relieved in the anomalous formation of porphodimethenes. Indeed, the difference in reactivity between $\mathrm{H}_{2} \mathrm{TtBuP}$ and $\mathrm{H}_{2} \mathrm{OETPP}$ was taken as an indication that the former might even be more distorted (both in solution and in the solid state) than are $\mathrm{H}_{2} \mathrm{OETPP}$ and its derivatives.

Using mild and brief reaction conditions for the metallation of $\mathrm{H}_{2} \mathrm{TtBuP}$, we have prepared a variety of metal complexes and obtained crystals of the pyridine adduct of $\mathrm{Zn}{ }^{\mathrm{IITtBuP}}$ suitable for a crystallographic structure determination. $\ddagger$ Fig. 1 shows the molecular structure in the crystal and gives some selected structural data. The illustration clearly indicates a nonplanar macrocyclic conformation. Surprisingly, the macrocyclic conformation is ruffled significantly as indicated by the tilt of the pyrrole planes against each other $\left(36^{\circ}\right)$ and the alternating up and down displacement of the $\mathrm{C}_{m}$ positions. Individual pyrrole rings are tilted on average by $26.3^{\circ}$ from the $4 \mathrm{~N}$ plane. This is in contrast to the nonplanar structures of dodecasubstituted free-base and zinc(II) porphyrins ${ }^{1-6}$ which so far have been shown to possess mostly saddle distortion. Ruffled conformations have been found e.g. in $\mathrm{Ni}^{\mathrm{II}}$ porphyrins, where the small metal ion induces ruffling owing to $\mathrm{Ni}-\mathrm{N}$ bond shortening. ${ }^{8}$ A strongly nonplanar ruffled conformation has also been found in the dodecasubstituted $\mathrm{Ni}^{\mathrm{II}}$ complex of
$2: 3,7: 8,12: 13,17: 18$-tetracyclopentenyl-5,10,15,20-tetra- $n$ pentylporphyrin $\left(\mathrm{H}_{2} \mathrm{TC}_{5} \mathrm{TPnP}\right)$ and it was suggested by molecular mechanics calculations that interaction of the methylene hydrogens of the $\mathrm{CH}_{2}$ group bound to the $\mathrm{C}_{m}$ position with the $\beta$-pyrrole substituents is responsible for the observed nonplanarity. ${ }^{3}$

The present structure shows that the presence of a bulky meso substituent alone (and its interaction with the $\beta$-pyrrole hydrogens) can lead to even more distorted macrocycles. Fig. 2 presents the deviations of the macrocycle atoms from the $4 \mathrm{~N}$ plane. The meso carbons show the largest deviations from planarity (average deviation $0.899 \AA$ ) and the average deviation

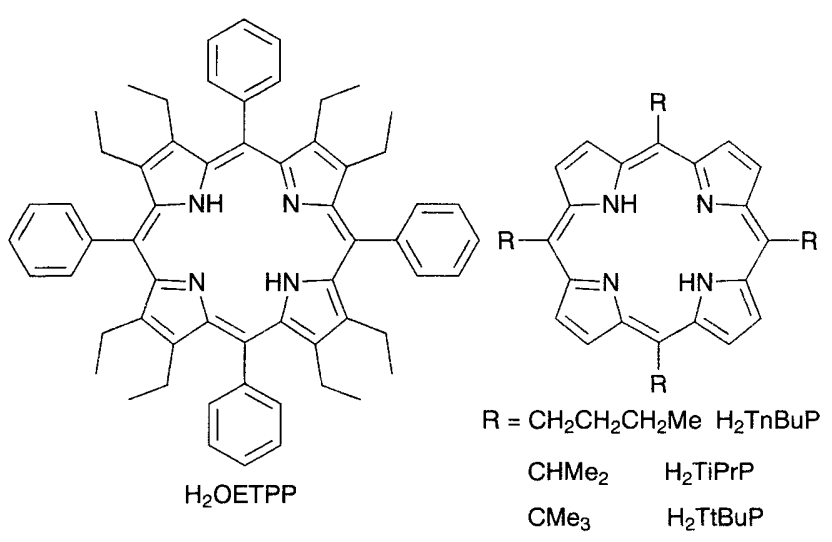

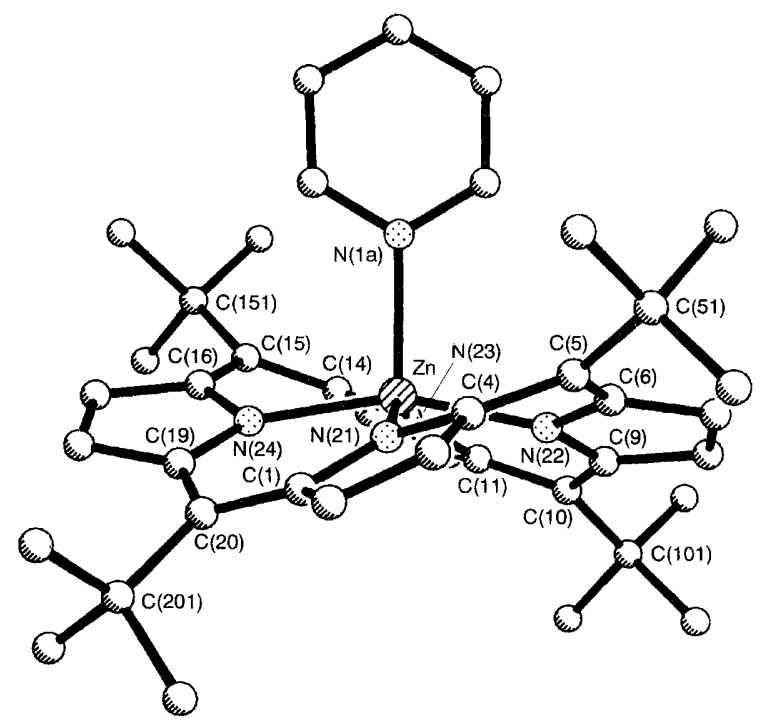

Fig. 1 View of the molecular structure of $\mathrm{Zn}^{\mathrm{IIT}} \mathrm{THuP}(\mathrm{pyr})$ in the crystal. Thermal ellipsoids are drawn for $50 \%$ occupancy; hydrogen atoms have been omitted for clarity. Selected bond lengths $(\AA)$ and angles $\left({ }^{\circ}\right): \mathrm{Zn}-$ $\mathrm{N}(1 \mathrm{~A}) \quad 2.165(4), \mathrm{Zn}-\mathrm{N}(21) \quad 2.024(5), \quad \mathrm{Zn}-\mathrm{N}(22) \quad 2.010(6), \quad \mathrm{Zn}-\mathrm{N}(23)$ 2.016(5), $\quad \mathrm{Zn}-\mathrm{N}(24) \quad 2.006(5), \quad \mathrm{C}(5)-\mathrm{C}(51) \quad 1.555(7), \quad \mathrm{C}(10)-\mathrm{C}(101)$ $1.558(8), \mathrm{C}(15)-\mathrm{C}(151) 1.556(9), \mathrm{C}(20)-\mathrm{C}(201) 1.561(7) ; \mathrm{C}(4)-\mathrm{C}(5)-\mathrm{C}(6)$ $120.5(4), \quad \mathrm{C}(9)-\mathrm{C}(10)-\mathrm{C}(11) \quad 121.2(5), \quad \mathrm{C}(14)-\mathrm{C}(15)-\mathrm{C}(16) \quad 121.3(6)$, $\mathrm{C}(19)-\mathrm{C}(20)-\mathrm{C}(1) 121.4(5)$. 
of all 24 macrocycle atoms from their least-squares plane is $0.442 \AA$. The distortion mode is quite different from that observed in, for example, the ruffled form of $\mathrm{NiOEP}^{8 b}$ where $\mathrm{S}_{4}$ ruffling is found. Here the distortion is asymmetric with regard to the two porphyrin faces. Larger displacements are observed for the $\mathrm{C}_{m}$ positions $[1 \AA$ for $\mathrm{C}(5)$ and $\mathrm{C}(15)$ versus $0.79 \AA$ for $C(10)$ and $C(20)$ ] bearing the tert-butyl groups pointing away from the side with the axial ligand, and similarily a smaller pyrrole tilt is found for the pyrroles bent towards the axial ligand. This shows that the presence of the axial ligand hinders further out-of-plane distortion on the porphyrin face bearing the axial ligand. The degree of ruffling found in the present compound with $\mathrm{C}_{m}$ displacements of about $1 \AA$ is so far unparalleled by any other porphyrin structure. The best known example for a ruffled porphyrin, $\mathrm{Ni}{ }^{I I} \mathrm{OEP}$, shows $\mathrm{C}_{m}$ displacements of $0.5 \AA .^{8 b}$ The coordination geometry about the pentacoordinated zinc(II) centre with its out-of-plane displacement by $0.39 \AA$ and an axial ligand $\mathrm{Zn}-\mathrm{N}_{\mathrm{L}}$ bond length of 2.165(4) $\AA$ agrees well with data found for other planar $^{9}$ and nonplanar ${ }^{2 a}$ porphyrins. The $\mathrm{Zn}-\mathrm{N}_{\mathrm{P}}$ bond lengths are on average 2.014(5) $\AA$, which is shorter than distances found in other $\mathrm{Zn}^{\mathrm{II}}$ porphyrins. This is in accord with data found for example for $\mathrm{Ni}^{\mathrm{II} O E P}$ with planar versus ruffled macrocycles. ${ }^{8 b}$

In order to address the question whether the nonplanar conformation found in the solid state is retained in solution, we have compared the absorption spectra of three related porphyrins. Prior work has shown that a direct correlation exists between the degree of bathochromically shifted absorption bands and the extent of macrocycle distortion. ${ }^{b}$ We chose $5,10,15,20$-tetra( $n$-butyl)porphyrin $\left(\mathrm{H}_{2} \mathrm{TnBuP}\right)$ as reference compound for a planar tetraalkylporphyrin. A comparison of this compound with $\mathrm{H}_{2} \mathrm{TtBuP}$ and 5,10,15,20-tetra(isopropyl)porphyrin $\left(\mathrm{H}_{2} \mathrm{TiPrP}\right)$, the $\mathrm{Ni}^{\mathrm{II}}$ complex ${ }^{7}$ of which exhibits $\mathrm{S}_{4}$ ruffling of a lesser degree than found in $\mathrm{H}_{2} \mathrm{TtBuP}$, is given in Table 1 . Both in the free base and zinc(II) series only small differences are found between the isopropyl and $n$-butyl derivatives, indicating a similar conformation, while in the dication series the isopropyl derivative shows somewhat more bathochromically shifted bands. $§$ The special case of $\mathrm{H}_{2} \mathrm{TtBuP}$ is clearly evidenced by the significantly red-shifted absorption

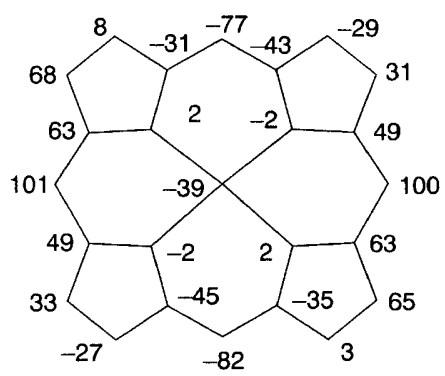

Fig. 2 Deviations $\left[\AA \times 10^{2}\right]$ of the macrocycle atoms in $\mathrm{Zn}{ }^{\mathrm{IIT}} \mathrm{TBuP}(\mathrm{pyr})$ from the least-squares plane of the four nitrogen atoms

Table 1 Absorption maxima and absorption coefficients of the porphyrins studied

\begin{tabular}{ll}
\hline Compound & $\lambda_{\max } / \mathrm{nm}\left(\varepsilon \times 10^{-3} / \mathrm{dm}^{3} \mathrm{~mol}^{-1} \mathrm{~cm}^{-1}\right)$ \\
\hline $\mathrm{H}_{2} \mathrm{TnBuP}$ & $416(174), 520(6.6), 556(4.5), 600(1.9), 658^{a}(3.2)$ \\
$\mathrm{H}_{2} \mathrm{TiPrP}$ & $420(186), 524(12.3), 560(6.4), 602(3.8), 656^{a}(4.2)$ \\
$\mathrm{H}_{2} \mathrm{TtBuP}$ & $446(305), 552(8.3), 596(5.5), 628(4.2), 692^{a}(1.7)$ \\
$\mathrm{ZnTnBuP}$ & $432(179), 572(30), 612^{b}(29)$ \\
$\mathrm{ZnTiPrP}$ & $430(182), 572(6.7), 614^{b}(4.9)$ \\
$\mathrm{ZnTtBuP}$ & $462(151), 610(11), 660^{b}(9.4)$ \\
{$\left[\mathrm{H}_{4} \mathrm{TnBuP}\right]^{2+}$} & $422(205), 586(3.9), 634^{c}(12.4)$ \\
{$\left[\mathrm{H}_{4} \mathrm{TiPrP}\right]^{2+}$} & $428(187), 594(4.7), 642^{c}(12.3)$ \\
{$\left[\mathrm{H}_{4} \mathrm{TtBuP}\right]^{2+}$} & $450(109), 706^{c}(1.2)$ \\
\hline
\end{tabular}

${ }^{a}$ In $\mathrm{CHCl}_{3} .{ }^{b}$ In pyridine. ${ }^{c}$ In $\mathrm{CH}_{2} \mathrm{Cl}_{2}$ containing $1 \%$ trifluoroacetic acid. bands. Compared to the $n$-butyl derivatives the Soret band in the $\mathrm{Zn}^{\mathrm{II}}$ derivative is shifted by $31 \mathrm{~nm}$ and the long wavelength band by $46 \mathrm{~nm}$. Even more drastic are the differences in the dication series with a red shift of $72 \mathrm{~nm}$ for the long wavelength absorption band upon going from the $n$ (butyl to the tert-butyl derivative. These data clearly indicate that a very nonplanar macrocycle conformation is retained in solution. The present structural data and the unusual reactivity observed for $\mathrm{H}_{2} \mathrm{TtBuP}$ make this and related derivatives very promising compounds for further mechanistic, structural and physicochemical investigations, which are currently in progress.

Support of this work from the National Institutes of Health (K. M. S., HL-22252) and the Deutsche Forschungsgemeinschaft (M. O. S.) is gratefully acknowledged.

\section{Received, 7th November 1994; Com. 4/06785A}

\section{Footnotes}

$\dagger$ New address: Institut für Organische Chemie (WE02), Freie Universität, Takustraße 3, D-14195 Berlin, Germany.

$\ddagger$ Crystal data for $\mathrm{Zn}{ }^{\mathrm{II}} \mathrm{TtBuP}(\mathrm{pyr})$ : small green plates were grown by slow diffusion of pyridine into a concentrated solution of $\mathrm{Zn}$ IITtBuP in methylene chloride. $\mathrm{C}_{41} \mathrm{H}_{49} \mathrm{~N}_{5} \mathrm{Zn}, M_{\mathrm{W}} 677.2$; triclinic, space group $P \overline{1}, a=11.838(5)$, $b=12.229(4), c=14.504(4) \AA, \alpha=102.96(2), \beta=112.40(2), \gamma=$ $104.87(3)^{\circ}, Z=2, V=1750.0(8) \AA^{3} ; D_{c}=1.285 \mathrm{Mg} \mathrm{m}^{-3}, \mu=1.243$ $\mathrm{mm}^{-1}$, Siemens P4 (RA) diffractometer, $\mathrm{Cu}-\mathrm{K} \alpha$ radiation, $\lambda=1.54178 \AA$, $T=118 \mathrm{~K}, 2 \theta_{\max }=112^{\circ}$, structure solution via Patterson synthesis, 4568 independent reflections, 3398 observed reflections with $F>4.0 \sigma(F), 424$ parameters, $R=0.0535, w R=0.0610, S=1.38$. Atomic coordinates, bond lengths and angles, and thermal parameters have been deposited at the Cambridge Crystallographic Data Centre. See Information for Authors, Issue No. 1.

$\S$ In the absence of definite structural data on the free base porphyrins, the possibility remains that both $\mathrm{H}_{2} \mathrm{TiPrP}$ and $\mathrm{H}_{2} \mathrm{TnBuP}$ might already be nonplanar. However, the strong red shifts observed for $\mathrm{H}_{2} \mathrm{TtBuP}$ clearly indicate a much higher degree of conformational distortion in this compound.

\section{References}

1 (a) M. B. Hursthouse and S. Neidle, J. Chem. Soc., Chem. Commun., 1972, 449; (b) K. M. Barkigia, L. Chantranupong, K. M. Smith and J. Fajer, J. Am. Chem. Soc, 1988, 110, 7566; (c) J. Fajer, Chem. Ind. (London), 1991, 869.

2 (a) K. M. Barkigia, M. D. Berber, J. Fajer, C. J. Medforth, M. W. Renner and K. M. Smith, J.Am. Chem. Soc., 1990, 112, 8851; L. D. Sparks, C. J. Medforth, M.-S. Park, J. R. Chamberlain, M. R. Ondrias, M. O. Senge, K. M. Smith and J. A. Shelnutt, J. Am. Chem. Soc., 1993, 115, 581; (b) K. M. Barkigia, M. W. Renner, L. R. Furenlid, C. J. Medforth, K. M. Smith and J. Fajer, J. Am. Chem. Soc., 1993, 115, 3627.

3 C. J. Medforth, M. O. Senge, K. M. Smith, L. D. Sparks and J. A. Shelnutt, J. Am. Chem. Soc., 1992, 114, 9859.

4 D. Mandon, P. Ochsenbein, J. Fischer, R. Weiss, K. Jayaraj, R. N. Austin, A. Gold, P. S. White, O. Brigaud, P. Battioni and D. Mansuy, Inorg. Chem., 1992, 31, 2044; P. Bhyrappa, V. Krishnan and M. Nethaji, J. Chem. Soc., Dalton Trans., 1993, 1901; W. P. Schaefer, J. A. Hodge, M. E. Hughes, H. B. Gray, J. E. Lyons, P. E. Ellis, Jr. and R. W. Wagner, Acta Crystallogr., Sect. C, 1993, 49, 1342; P. Ochsenbein, K. Ayougou, D. Mandon, J. Fischer, R. Weiss, R. N. Austin, K. Jayaraj, A. Gold, J. Terner and J. Fajer, Angew. Chem., Int. Ed. Engl., 1993, 33, 348.

5 N.-J. Zhu, Y. Li, G.-Z. Wu and X.-G. Liang, Acta Chim. Sin., 1992, 50, 249; M. O. Senge, J. Chem. Soc., Dalton Trans., 1993, 3539.

6 M. O. Senge, C. J. Medforth, L. D. Sparks, J. A. Shelnutt and K. M. Smith, Inorg. Chem., 1993, 32, 1716.

7 T. Ema, M. O. Senge, N. Y. Nelson, H. Ogoshi and K. M. Smith, Angew. Chem., Int. Ed. Engl., 1994, 33, 1879.

8 (a) W. R. Scheidt and Y. J. Lee, Struct. Bonding (Berlin), 1987, 64, 1; (b) E. F. Meyer, Jr., Acta Crystallogr., Sect. B, 1972, 28, 2162; D. L. Cullen and E. F. Meyer, Jr., J. Am. Chem. Soc., 1974, 96, 2095; T. D. Brennan, W. R. Scheidt and J. A. Shelnutt, J. Am. Chem. Soc., 1988, 110 3919.

9 D. M. Collins and J. L. Hoard, J. Am. Chem. Soc., 1970, 92, 3761; D. L. Cullen and E. F. Meyer, Jr., Acta Crystallogr., Sect. B, 1976, 32, 2259. 